\title{
RIPK4/PEBP1 axis promotes pancreatic cancer cell migration and invasion by activating RAF1/MEK/ERK signaling
}

\author{
ZI-HAO QI ${ }^{1-4^{*}}$, HUA-XIANG XU ${ }^{1-4^{*}}$, SHI-RONG ZHANG ${ }^{1-4},{\mathrm{JIN}-Z H I ~ X U^{1-4}}$, SHUO LI $^{1-4}$, HE-LI GAO $^{1-4}$, \\ WEI JIN $^{1-4}$, WEN-QUAN WANG ${ }^{1-4}$, CHUN-TAO WU ${ }^{1-4}$, QUAN-XING NI ${ }^{1-4}$, XIAN-JUN YU ${ }^{1-4}$ and LIANG LIU ${ }^{1-4}$ \\ ${ }^{1}$ Department of Pancreatic Surgery, Fudan University Shanghai Cancer Center; ${ }^{2}$ Department of Oncology, \\ Shanghai Medical College, Fudan University; ${ }^{3}$ Shanghai Pancreatic Cancer Institute; \\ ${ }^{4}$ Pancreatic Cancer Institute, Fudan University, Shanghai 200032, P.R. China
}

Received November 15, 2017; Accepted January 22, 2018

DOI: $10.3892 /$ ijo.2018.4269

\begin{abstract}
Pancreatic cancer is a lethal disease with a high metastatic potential. In our previous study, we identified a specific subgroup of patients with pancreatic cancer with a serum signature of carcinoembryonic antigen $(\mathrm{CEA})^{+} /$cancer antigen (CA) $125^{+} / \mathrm{CA} 19-9 \geq 1,000 \mathrm{U} / \mathrm{ml}$. In this study, by using high-throughput screening analysis, we found that receptorinteracting protein kinases 4 (RIPK4) may be a key molecule involved in the high metastatic potential of this subgroup of patients with pancreatic cancer. A high RIPK4 expression predicted a poor prognosis and promoted pancreatic cancer cell migration and invasion via the RAF1/MEK/ERK pathway. Moreover, RIPK4 activated the RAF1/MEK/ERK pathway by regulating proteasome-mediated phosphatidylethanolamine binding protein 1 (PEBP1) degradation. The suppression of PEBP1 degradation eliminated the RIPK4-induced activation of RAF1/MEK/ERK signaling and pancreatic cancer cell migration or invasion. Thus, on the whole, the findings of this study indicated that RIPK4 was upregulated in the subgroup of pancreatic cancer with a high metastatic potential. RIPK4 overexpression promoted pancreatic cancer cell migration and invasion via the PEBP1 degradation-induced activation of the RAF1/MEK/ERK pathway.
\end{abstract}

\section{Introduction}

Pancreatic cancer is one of the most lethal solid tumors with a 5 -year survival rate for $\sim 6 \%(1,2)$. Surgical resection remains

Correspondence to: Professor Xian-Jun Yu or Professor Liang Liu, Department of Pancreatic Surgery, Fudan University Shanghai Cancer Center, 270 Dong An Road, Shanghai 200032, P.R. China E-mail: yuxianjun@fudanpci.org

E-mail: liuliang@fudanpci.org

${ }^{*}$ Contributed equally

Key words: pancreatic cancer, receptor-interacting protein kinase 4, RAF1/MEK/ERK pathway, phosphatidylethanolamine binding protein 1 , tumor metastasis the most effective treatment $(3,4)$; however, a significant number of patients that undergo radical pancreatectomy experience early local recurrence and metastasis $(5,6)$. We previously reported a subgroup of patients with pancreatic cancer with a serum signature of carcinoembryonic antigen (CEA) ${ }^{+} /$cancer antigen (CA) $125^{+} / \mathrm{CA} 19-9 \geq 1,000 \mathrm{U} / \mathrm{ml}$, who were more likely to experience metastasis within 6 months following radical resection (7). Exploring the molecular mechanisms responsible for this subgroup with a high metastatic potential may clarify the biological mechanisms responsible for the high metastatic potential in pancreatic cancer and may improve the prognosis of patients with this lethal disease.

Receptor-interacting protein kinase 4 (RIPK4) is a member of the receptor-interacting protein (RIP) kinase family. It interacts with protein kinase $\mathrm{C}-\delta(\mathrm{PKC} \delta)$ and exhibits protein kinase activity toward autophosphorylation and substrate phosphorylation $(8,9)$. RIPK4 dysregulation contributes to tumor occurrence and development in human cancers (10-14); however, its role in pancreatic cancer remains unclear. Phosphatidylethanolamine-binding protein 1 (PEBP1), also known as RAF kinase inhibitory protein (RKIP), is a physiological endogenous inhibitor of the mitogen-activated protein kinase (MAPK) pathway (15). It interferes with RAF1-mediated phosphorylation and MAPK kinase (MEK) activation via its ability to disrupt the interaction between the two kinases (16). It has been suggested that PEBP1 is a suppressor of metastasis in pancreatic cancer, and its expression is lost in more than half of patients with pancreatic cancer (17). The loss of PEBP1 expression is significantly associated with pancreatic cancer metastasis (18), and a poor overall survival (OS) and diseasefree survival (DFS) (19). Although the effect of PEBP1 on MAPK pathway can be regulated by $\operatorname{PKC~}(20,21)$, the association between PEBP1 and RIPK4, which interacts with PKCס, remains unclear.

In the present study, we demonstrate that RIPK4 is highly expressed in the high metastatic potential subgroup of patients with pancreatic cancer with $\mathrm{CEA}^{+} / \mathrm{CA}_{125} / \mathrm{CA} 19-9$ $\geq 1,000 \mathrm{U} / \mathrm{ml}$. A high RIPK4 expression correlated with a poor prognosis and promoted pancreatic cancer cell migration and invasion. Mechanistically, these functions are in part due to its ability to activate RAF1/MEK/ERK signaling via the regulation of PEBP1 degradation. These results illuminate 
the biological mechanisms responsible for the high metastatic potential of pancreatic cancer and may aid in the identification of novel therapeutic targets.

\section{Materials and methods}

Cell lines and cell culture. The human pancreatic cancer cell lines, PANC-1, MIA PaCa-2, Capan-1, BxPC-3, SW1990 and CFPAC-1, were purchased from the American Type Culture Collection (ATCC, Manassas, VA, USA). The culture medium, subculturing, cryopreservation and culture conditions were according to standard ATCC methods. Human pancreatic duct epithelial (HPDE) cells were a kind gift from Professor Tsao (22). The cells were grown in DMEM containing $10 \%$ fetal bovine serum (FBS) at $37^{\circ} \mathrm{C}$ under a humidified $5 \% \mathrm{CO}_{2}$ atmosphere. U0126 and MG132 were purchased from Selleck Chemicals (Houston, TX, USA). To determine whether the expression levels of PEBP1 proteins are regulated through proteasome-mediated degradation, the cells were exposed with $10 \mu \mathrm{M}$ MG132 for $3 \mathrm{~h}$ and then harvested for western blot analysis. In addition, to examine the effect of the suppression of PEBP1 degradation with MG132 on RAF1/MEK/ERK pathway activation, the cells were exposed to $1 \mu \mathrm{M}$ MG132 for $24 \mathrm{~h}$ and then harvested for western blot analysis.

Patients and tissue specimens. The human pancreatic cancer tissues used in this study were collected from patients diagnosed with pancreatic adenocarcinoma who underwent radical resection at the Fudan University Shanghai Cancer Center between 2010 and 2013. The use of human tissues was approved by the Fudan University Shanghai Cancer Center Institutional Research Ethics Committee and patient consent was obtained. The histological grading and pathological annotation were performed by two independent pathologists at our center. A total of 79 samples were available for the construction of tissue microarrays (TMAs) and the evaluation of RIPK4 expression. The clinicopathological characteristics of the patients are listed in Table I. The patients were followed-up until December 2016. In total, 34 cases were used to examine the association between RIPK4 and PEBP1 expression.

Microarray analysis. Affymetrix Human U133 plus 2.0 (Affymetrix, Santa Clara, CA, USA) was used to compare differentially expressed genes between 8 patients with pre-operative serum $\mathrm{CEA}^{+} / \mathrm{CA} 125^{+} / \mathrm{CA} 19-9 \geq 1,000 \mathrm{U} / \mathrm{ml}$ $\left(\mathrm{CEA}^{+}, \mathrm{CEA} \geq 5.2 \mathrm{ng} / \mathrm{ml} ; \mathrm{CA} 125^{+}, \mathrm{CA} 125 \geq 35 \mathrm{U} / \mathrm{ml}\right)$ and a DFS of $\leq 6$ months, and 8 patients with pre-operative serum $\mathrm{CEA}^{-} / \mathrm{CA}^{2}{ }^{-/ \mathrm{CA} 19-9} \leq 37 \mathrm{U} / \mathrm{ml}\left(\mathrm{CEA}^{-}, \mathrm{CEA}<5.2 \mathrm{ng} / \mathrm{ml}\right.$; CA125', CA125<35 U/ml) and a DFS of $\geq 24$ months. The latter subgroup of patients with pancreatic cancer had a low metastatic potential and a better prognosis. Pre-operative levels of such tumor markers were determined within 1 week prior to resection. The normal upper limits of serum tumor markers are listed here CA19-9 (37 U/ml), CEA (5.2 ng/ml) and CA125 (35 U/ml). The Database for Annotation, Visualization and Integrated Discovery (DAVID) was used to identify pathways and processes of major biological significance and importance based on the Gene Ontology (GO) annotation function and Kyoto Encyclopedia of Genes and Genomes (KEGG) pathway function.
Western blot analysis. Western blot analysis was carried out as previously described (23). In brief, the cells were harvested after being washed with phosphate-buffered saline (PBS) twice, lysed with RIPA cell lysis buffer for $30 \mathrm{~min}$ on ice, and centrifuged at $12,000 \mathrm{rpm}$ for $15 \mathrm{~min}$ at $4^{\circ} \mathrm{C}$. The concentration of total protein was determined using a BCA protein assay kit. Equal amounts (30 $\mu \mathrm{g} / \mathrm{load})$ of protein samples were subjected to sodium dodecyl sulfate-polyacrylamide gel electrophoresis (SDS-PAGE) electrophoresis and transferred onto polyvinylidene fluoride (PVDF) membranes and reacted with primary antibodies overnight at $4^{\circ} \mathrm{C}$. Following incubation with the secondary antibodies for $1 \mathrm{~h}$ at room temperature, the protein bands were developed with the chemiluminescent reagents and imaged by ImageQuant ${ }^{\mathrm{TM}}$ LAS 4000 (GE Healthcare, Little Chalfont, Buckinghamshire, UK). Antibodies against the following proteins were obtained from Santa Cruz Biotechnology (Santa Cruz, CA, USA): RIPK4 (sc-377368), RAF1 (sc-7267), MEK1/2 (sc-436), p-MEK1/2 (sc-81503), p-ERK1/2 (sc-136521), RKIP (sc-376925) and p-RKIP (sc-135779). Antibodies against ERK1/2 (cs-9102) and p-RAF1 (cs-9427) were obtained from Cell Signaling Technology (Danvers, MA, USA). All these antibodies mentioned above were diluted at 1:1,000. $\beta$-actin expression (A2228; Sigma-Aldrich, St. Louis, MO, USA) was used as a loading control at a dilution of 1:40,000. Anti-mouse IgG antibody (cs-14709) and anti-rabbit IgG (cs-14708) which were obtained from Cell Signaling Technology were used as the secondary antibodies at a dilution of 1:3,000.

Immunohistochemistry. Immunohistochemical staining for RIPK4 (sc-377368) or PEBP1 (sc-376925) was carried out according to standard procedures. The percentage of tumor cells with RIPK4 or PEBP1 staining was evaluated $(0 \%, 0 ; 1-10 \%, 1 ; 11-50 \%, 2 ; 51-80 \%, 3$ and $81-100 \%, 4)$. The staining intensity was evaluated as follows: 0 , negative; 1, weak; 2, moderate; and 3, strong. The numeric values were multiplied to yield an immunoreactivity score (IRS) ranging from 0 to 12 . The cut-off point for RIPK4 and PEBP1 expression (high vs. low) was determined using a median IRS score. The definition for high RIPK4 and PEBP1 was IRS $\geq 7$ (at least moderate intensity in $>50 \%$ of tumor cells or at least strong intensity in $>10 \%$ of tumor cells). IRS scores were evaluated by two pathologists. Correlations between RIPK4 and PEBP1 were analyzed with Pearson's $\chi^{2}$ tests.

Plasmid construction and cell lines. The shRNA oligos targeting human RIPK4 (GCACGATGTATACAGCTTTGC and GGAACCTTCAACCAGCGATCT) were designed and cloned into the pLKO.1-TRC (Plasmid 10878; Addgene, Cambridge, MA, USA) cloning vector to generate shRNA constructs. The human RIPK4 coding sequence was cloned into the lentiviral vector pLENT-EF1 $\alpha$-Puro-CMV to generate RIPK4 expression plasmids. A pLKO.1-scramble shRNA (Plasmid 1864; Addgene) and a lentiviral vector pLENT-EF1 $\alpha$ Puro-CMV were used as the negative control. A lentiviral vector pLV-luci (Cat\#VL3612; Inovogen, Beijing, China) was used to express luciferase in tumor cells. The recombinant construct was co-transfected into $293 \mathrm{~T}$ cells together with two packaging vectors (psPAX2 and pMD2.G). Lentiviral particles were harvested and filtered to infect pancreatic cancer cell lines 
Table I. Correlation of clinicopathological characteristics and with RIPK4 expression in PDAC tissue samples.

\begin{tabular}{|c|c|c|c|c|}
\hline \multirow[b]{2}{*}{ Characteristic } & \multirow[b]{2}{*}{ No. } & \multicolumn{3}{|c|}{ RIPK4 expression } \\
\hline & & $\begin{array}{l}\text { Negative/low } \\
\quad(n=52)\end{array}$ & $\begin{array}{l}\text { High } \\
(n=27)\end{array}$ & P-value \\
\hline \multicolumn{5}{|l|}{ Age } \\
\hline$\leq 60$ years & 38 & 26 & 12 & 0.8127 \\
\hline$>60$ years & 41 & 26 & 15 & \\
\hline \multicolumn{5}{|l|}{ Sex } \\
\hline Female & 44 & 25 & 19 & 0.0938 \\
\hline Male & 35 & 27 & 8 & \\
\hline \multicolumn{5}{|l|}{ Tumor location } \\
\hline Head & 37 & 25 & 12 & 0.8151 \\
\hline Body and tail & 42 & 27 & 15 & \\
\hline \multicolumn{5}{|l|}{ Tumor size } \\
\hline$\leq 3.0 \mathrm{~cm}$ & 32 & 22 & 10 & 0.8096 \\
\hline$>3.0 \mathrm{~cm}$ & 47 & 30 & 17 & \\
\hline \multicolumn{5}{|c|}{ Lymph node status } \\
\hline Negative & 31 & 23 & 8 & 0.2340 \\
\hline Positive & 48 & 29 & 19 & \\
\hline \multicolumn{5}{|c|}{ Tumor differentiation } \\
\hline Well & 7 & 3 & 4 & $0.4064^{\mathrm{b}}$ \\
\hline Moderate & 47 & 32 & 15 & \\
\hline Poor & 25 & 17 & 8 & \\
\hline \multicolumn{5}{|c|}{ TNM stage (UICC) } \\
\hline IB & 12 & 11 & 1 & $0.0488^{\mathrm{b}}$ \\
\hline IIA & 19 & 14 & 5 & \\
\hline IIB & 48 & 27 & 21 & \\
\hline
\end{tabular}

UICC, International Union Against Cancer. ${ }^{a} F i s h e r ' s$ exact test; ${ }^{\mathrm{b}} \chi^{2}$ test. RIPK4, receptor-interacting protein kinases 4 .

followed by puromycin screening to generate stable cells with RIPK4 overexpression or knockdown. RIPK4 was overexpressed in the Capan-1 (Capan-1-R) and SW1990 (SW1990-R) cells; RIPK4 was knocked down in the PANC-1 (PANC-1-Rsh1, PANC-1-Rsh2) and MIA PaCa-2 (MIA2-Rsh1, MIA2-Rsh2) cells. The control cells were Capan-1-vector (Capan-1-vec), SW1990-vector (SW1990-vec), PANC-1-scramble (PANC1-src) and MIA PaCa-2-scramble (MIA2-src).

Transwell cell migration and invasion assay. The cells $\left(5 \times 10^{4}\right)$ were seeded into the upper chamber (24-well insert; Corning, Corning, NY, USA). The lower chamber was filled with $10 \%$ FBS followed by incubation for 48 or $72 \mathrm{~h}$ for the migration or invasion assays, respectively. For the invasion assay, the inserts were previously coated with extracellular matrix gel (BD Biosciences, San Jose, CA, USA). The cells on the lower surface were fixed with $4 \%$ paraformaldehyde and stained with $0.05 \%$ crystal violet. Three visual fields were randomly selected, and the numbers of cells were counted under a microscope (IX71; Olympus, Tokyo, Japan). To examine the effect of the suppression of PEBP1 degradation by MG132 and blocking RAF1/MEK/ERK signaling by U0126 on cell migration and invasion, the cells were exposed with $1 \mu \mathrm{M}$ MG132 for $24 \mathrm{~h}$ and $10 \mu \mathrm{M} \mathrm{U} 0126$ for $8 \mathrm{~h}$ before the cells were trypsinized and seeded onto the upper chamber of the Transwell, respectively. DMSO was used as the control.

Establishment of xenograft tumors using nude mice. A total of 12 BALB/c-nu mice (female, 4-5 weeks of age; weighing 18-20 g; SLAC Laboratory Animal Co., Ltd., Shanghai, China) were randomly assigned to 2 groups, and 3×106 SW1990 luciferase-tagged pancreatic cancer cells with or without RIPK4 overexpression in $100 \mu \mathrm{l}$ PBS were injected into the spleens of the mice in the 2 groups. At 3 weeks after implantation, the mice were prepared for IVIS Spectrum In Vivo Imaging System scanning. After the final imaging, the tumors and tissue specimens of the mice were surgically dissected after the mice were sacrificed by cervical dislocation for the observation of metastasis and follow-up experiments. All animal experiments were approved by the Institutional Animal Care and Use Committee of Fudan University.

GEO database analysis. To identify the clinical relevance of increased RIPK4 expression, we used the Gene Expression Omnibus (GEO) database (https://www.ncbi.nlm.nih.gov/geo). The expression data from Mayo Clinic pancreatic tumor and normal samples are available through GEO (accession no. GSE16515). The experiment consisted of 36 tumor samples and 16 normal samples; a total of 52 samples. The raw data were downloaded from GEO and affymerix oligo array probe level data were converted to expression values using $\mathrm{R}$ software. The gene expression level was normalized to the RPKM value.

Network analysis. We used the predictive web interface GeneMANIA (http://www.genemania.org) to predict interactions between RIPK4 and the MAPK signaling pathway. The analysis generated a list of genes with functional similarity based on currently available proteomics and genomics databases (24).

Quantitative (real-time) PCR. Total RNA was extracted using TRIzol reagent (Invitrogen, Carlsbad, CA, USA). The RNA was then reverse transcribed into cDNA with the ExScript reverse transcription-polymerase chain reaction (RT-PCR) kit (Takara, Tokyo, Japan). The expression status of PEBP1 and glyceraldehyde 3-phosphate dehydrogenase (GAPDH) were determined by quantitative PCR. GAPDH was used as the loading control. The following oligonucleotide primer was used: PEBP1 forward, 5'-CTCCGATTATGTGGGCTCGG-3' and reverse, 5'-GGT GGTCTCCAGATCGGTTG-3'; and GAPDH forward, 5'-CGA CCACTTTGTCAAGCTCA-3' and reverse, 5'-AGGGGAGAT TCAGTGTGGTG-3'. All amplifications and detections were carried out using the Applied Biosystems Prism 7900 system (Applied Biosystems, Foster City, CA, USA). The assays were performed in triplicate.

Statistical analysis. The results are expressed as the means \pm SD. Two-tailed unpaired Student's t-tests, one-way analysis of variance, or Pearson's $\chi^{2}$ tests were used to evaluate 
Table II. Differentially expressed genes in human pancreatic cancer samples $\left(\mathrm{CEA}^{+} / \mathrm{CA} 125^{+} / \mathrm{CA} 19-9 \geq 1,000 \mathrm{U} / \mathrm{ml}\right.$, DFS of $\leq 6$ months vs. CEA $\%$ CA125/CA19-9 $\leq 37 \mathrm{U} / \mathrm{ml}$, DFS of $\geq 24$ months).

\begin{tabular}{lllll}
\hline & Probe_Set_ID & Gene_symbol & P-value & Fold change $^{\text {a }}$ \\
\hline Upregulated gene & 205922_at & VNN2 & 0.03327158 & 2.761510733 \\
& 206336_at & CXCL6 & 0.030429421 & 2.682334096 \\
213150_at & HOXA10 & 0.015566485 & 2.648941024 \\
204006_s_at & FCGR3A/FCGR3B & 0.032846977 & 2.459635693 \\
1569344_a_at & - & 0.034275931 & 2.421933712 \\
& 226926_at & DMKN & 0.019513244 & 2.310987677 \\
221215_s_at & RIPK4 & 0.036130949 & 2.231740768 \\
& 211504_x_at & ROCK2 & 0.020972521 & 2.132222303 \\
222830_at & GRHL1 & 0.029119833 & 2.122296769 \\
Downregulated gene & 213268_at & CAMTAI & 0.003757686 & 0.495911419 \\
& 209465_x_at & PTN & 0.01256999 & 0.484851788 \\
& 203896_s_at & PLCB4 & 0.011971674 & 0.479533229 \\
& 235645_at & ESCOI & 0.012775165 & 0.472722222 \\
244700_at & SEC61B & 0.008219772 & 0.466590487 \\
& 243790_at & ZNF585A & 0.033921682 & 0.46249514 \\
211737_x_at & PTN & 0.025599908 & 0.448126885 \\
& 241803_s_at & & 0.029068249 & 0.382177815 \\
\hline
\end{tabular}

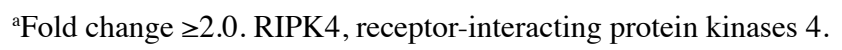

the data. Survival curves were plotted using the Kaplan-Meier method and compared by the log-rank test. All statistical analyses were performed using SPSS 19.0 software (IBM Corp., Armonk, NY, USA). Differences were considered significant at $\mathrm{P}<0.05$.

\section{Results}

RIPK4 expression is upregulated in pancreatic cancer and is associated with a poor outcome following surgery and a high metastatic potential. A cDNA microarray was used to perform the contrastive analysis of the gene expression profiles between 8 patients with pre-operative serum $\mathrm{CEA}^{+} / \mathrm{CA} 125^{+} / \mathrm{CA} 19-9$ $\geq 1,000 \mathrm{U} / \mathrm{ml}$, DFS of $\leq 6$ months, and 8 patients with pre-operative serum CEA $/ \mathrm{CA} 125^{-} / \mathrm{CA} 19-9 \leq 37 \mathrm{U} / \mathrm{ml}$, a DFS of $\geq 24$ months. Over 100 genes had at least a 1.5 -fold difference in expression between the 2 groups $(\mathrm{P}<0.05)$ (Fig. 1A), and 17 genes were differentially expressed with at least a 2 -fold change in expression $(\mathrm{P}<0.05)$ (Table II). The RIPK4 mRNA levels were upregulated by 2.2 -fold. To determine the clinical relevance of the increased expression of RIPK4, we first analyzed the RIPK4 mRNA levels in 52 clinical specimens (GSE16515), including 36 pancreatic cancer tissue specimens and 16 normal pancreatic tissue specimens, which are available through the Gene Expression Omnibus (GEO) database. The RIPK4 mRNA level (normalized to the RPKM value) was higher in the pancreatic cancer tissues than in the normal pancreatic tissues $(\mathrm{P}<0.05)$ (Fig. 1B). A survival analyses using the clinical and follow-up TCGA pancreatic cancer data revealed that the patients with a high RIPK4 expression had a shorter OS than those with low RIPK4 levels (17.7 vs. 22.2 months, $\mathrm{P}<0.05$ ) (Fig. 1C).
Immunohistochemistry was performed to detect RIPK4 protein expression in a TMA of 79 pancreatic cancer tissues. RIPK4 localized to the cell membrane and cytoplasm and was detectable in $70(89 \%)$ cases. Representative samples are shown in Fig. 1D. In total, 52 (66\%) cases were defined as having a negative/low expression, and 27 (34\%) had a high expression (Fig. 1D and E). Survival analyses revealed that a high RIPK4 expression was associated with a decreased OS (14.7 vs. 19.6 months, $\mathrm{P}<0.05)$ and DFS (8.5 vs. 12.3 months, $\mathrm{P}<0.05$ ) (Fig. $1 \mathrm{~F}$ and $\mathrm{G}$ ). These findings suggest that a higher RIPK4 expression is associated with a poor outcome and tumor metastasis in patients with pancreatic cancer.

RIPK4 promotes pancreatic cancer cell migration and invasion in vitro and in vivo. Western blot analysis was used to determine the RIPK4 protein levels in several pancreatic cancer cell lines. The results revealed a high expression in the MIA PaCa-2, PANC-1 and CFPAC-1 cells; a low expression in the Capan-1, BxPC-3 and SW1990 cells; and barely detectable levels in HDPE cells (Fig. 2A). RIPK4 was then overexpressed in the Capan-1 and SW1990 cells, and knocked down in the PANC-1 and MIA PaCa-2 cells (Fig. 2B). Transwell cell migration/invasion assays revealed that RIPK4 knockdown with shRNA oligos markedly decreased the number of PANC-1 and MIA PaCa-2 migrating/invading cells [PANC-1 migrating cells: $327 \pm 83$ vs. $68 \pm 20, \mathrm{P}<0.05 ; 327 \pm 83$ vs. $89 \pm 10$, $\mathrm{P}<0.05$; PANC-1 invading cells: $504 \pm 74$ vs. $160 \pm 66, \mathrm{P}<0.05$; $504 \pm 74$ vs. $185 \pm 60, \mathrm{P}<0.05$; and $\mathrm{MIA} \mathrm{PaCa}-2$ migrating cells: $270 \pm 72$ vs. $109 \pm 24, \mathrm{P}<0.05 ; 270 \pm 72$ vs. $77 \pm 20, \mathrm{P}<0.05$; MIA PaCa-2 invading cells: $257 \pm 65$ vs. $100 \pm 25, \mathrm{P}<0.05$; $257 \pm 65$ vs. $100 \pm 51, \mathrm{P}<0.05$ (PANC-1-Scr vs. PANC-1-Rsh1 and PANC-1-Scr vs. PANC-1-Rsh2, respectively and 
A

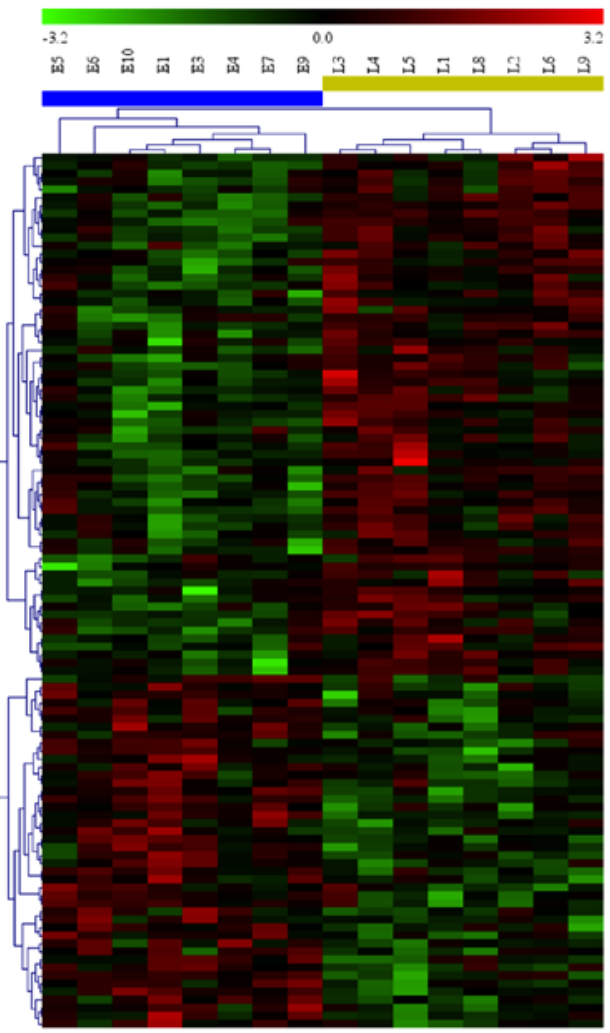

D
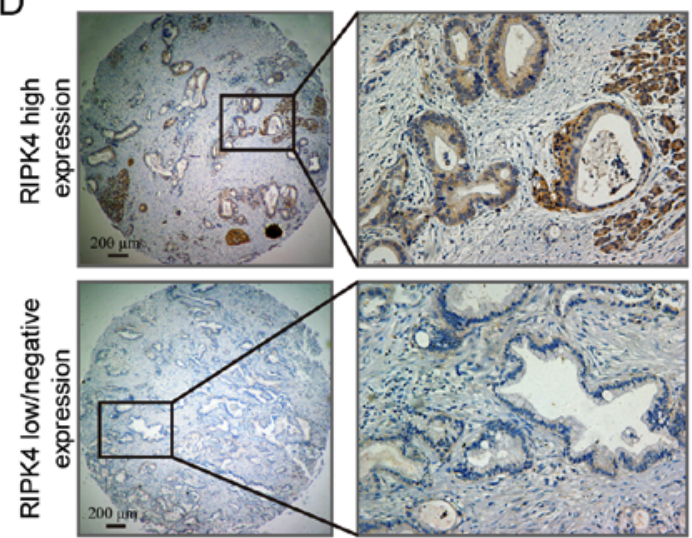

E

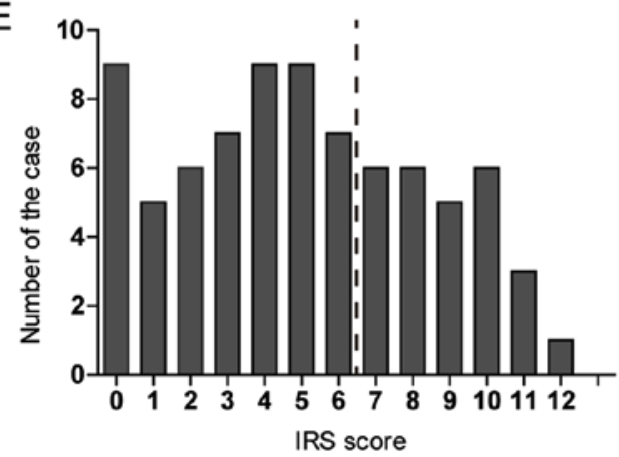

B

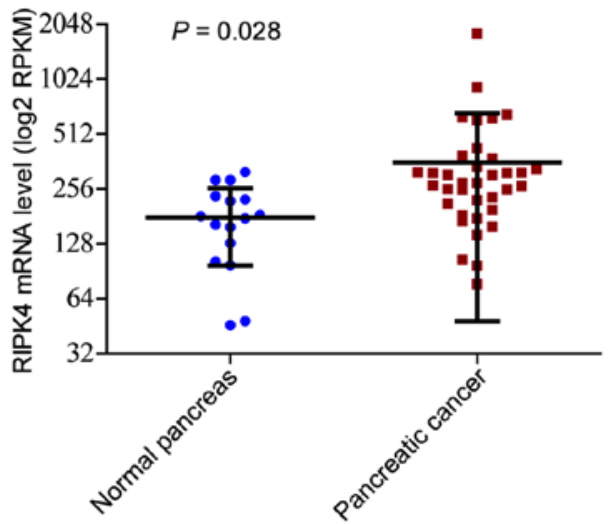

C

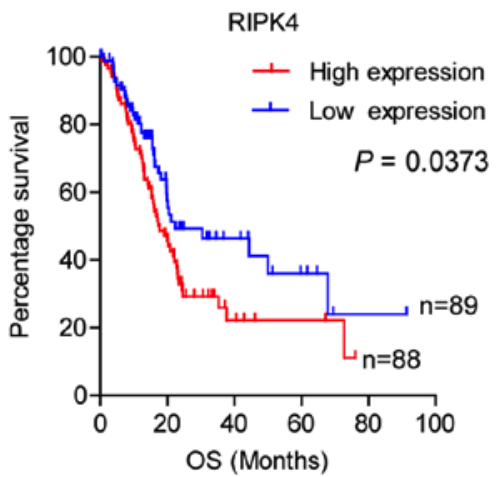

F

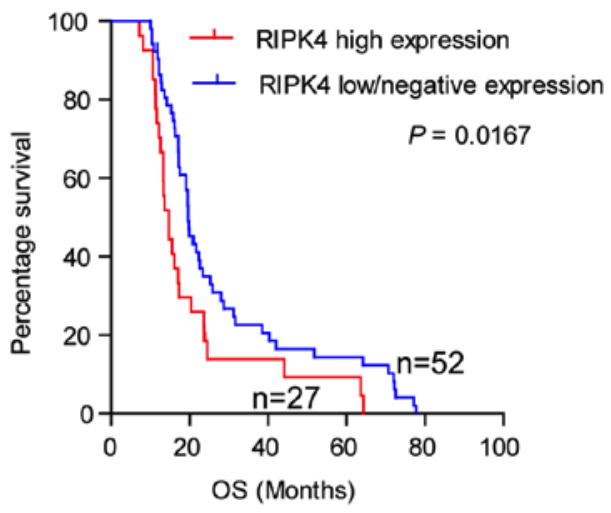

G

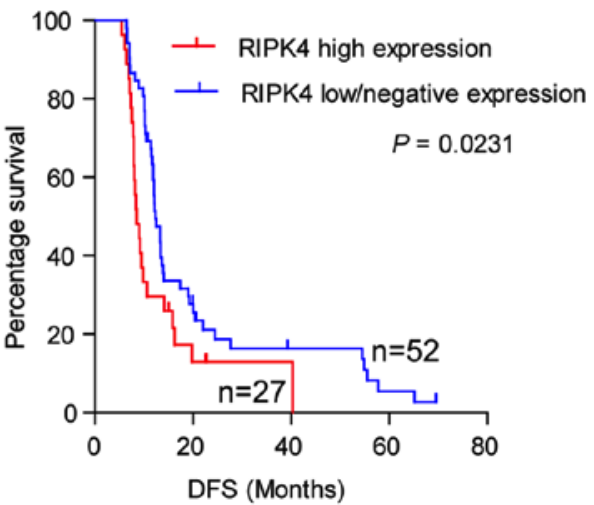

Figure 1. Receptor-interacting protein kinases 4 (RIPK4) expression is upregulated in pancreatic cancer and is associated with a poor prognosis. (A) Differentially expressed genes with at least a 1.5-fold change in expression screened by cDNA microarray. (B) RIPK4 mRNA expression was determined in 36 PDAC tissue specimens and 16 normal pancreatic tissue specimens from the GEO database. (C) RIPK4 survival analyses using the TCGA pancreatic cancer data. (D) RIPK4 protein expression was examined by tissue microarray; representative images are shown. (E) RIPK4 expression IRS scores in the tissue microarray. (F and G) Kaplan-Meier survival analyses were conducted to evaluate the effect of RIPK4 on overall and disease-free survival.

MIA2-Scr vs. MIA2-Rsh1 and MIA2-Scr vs. MIA2-Rsh2, respectively) (Fig. 2C-F)]. Consistent with these findings, RIPK4 overexpression markedly increased the number of migrating/invading Capan-1 and SW1990 cells [Capan-1 migrating cells: $64 \pm 25$ vs. $193 \pm 37, \mathrm{P}<0.05$; Capan-1 invading cells: $54 \pm 20$ vs. $175 \pm 25, \mathrm{P}<0.05$; and SW1990 migrating 
A

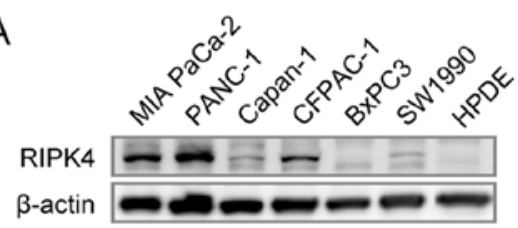

B

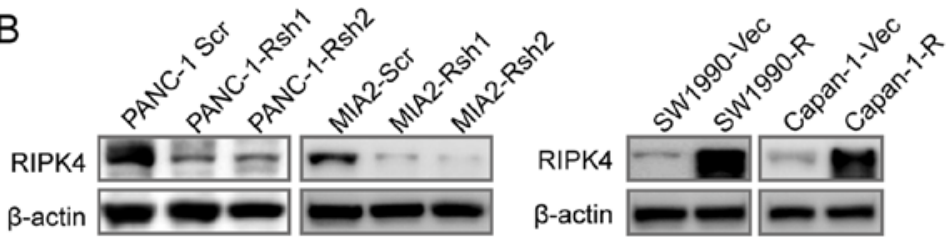

C
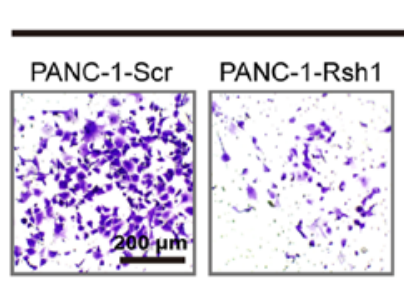

Migration
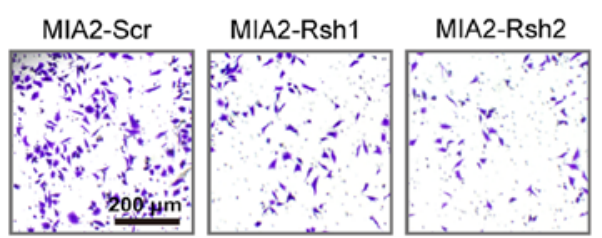

$\mathrm{E}$
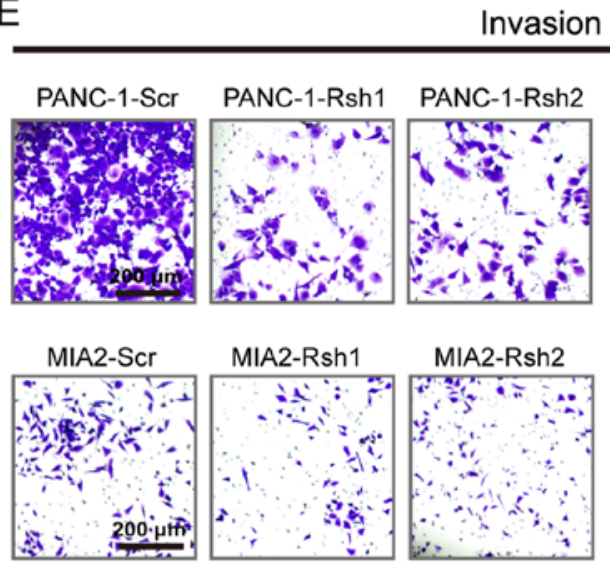
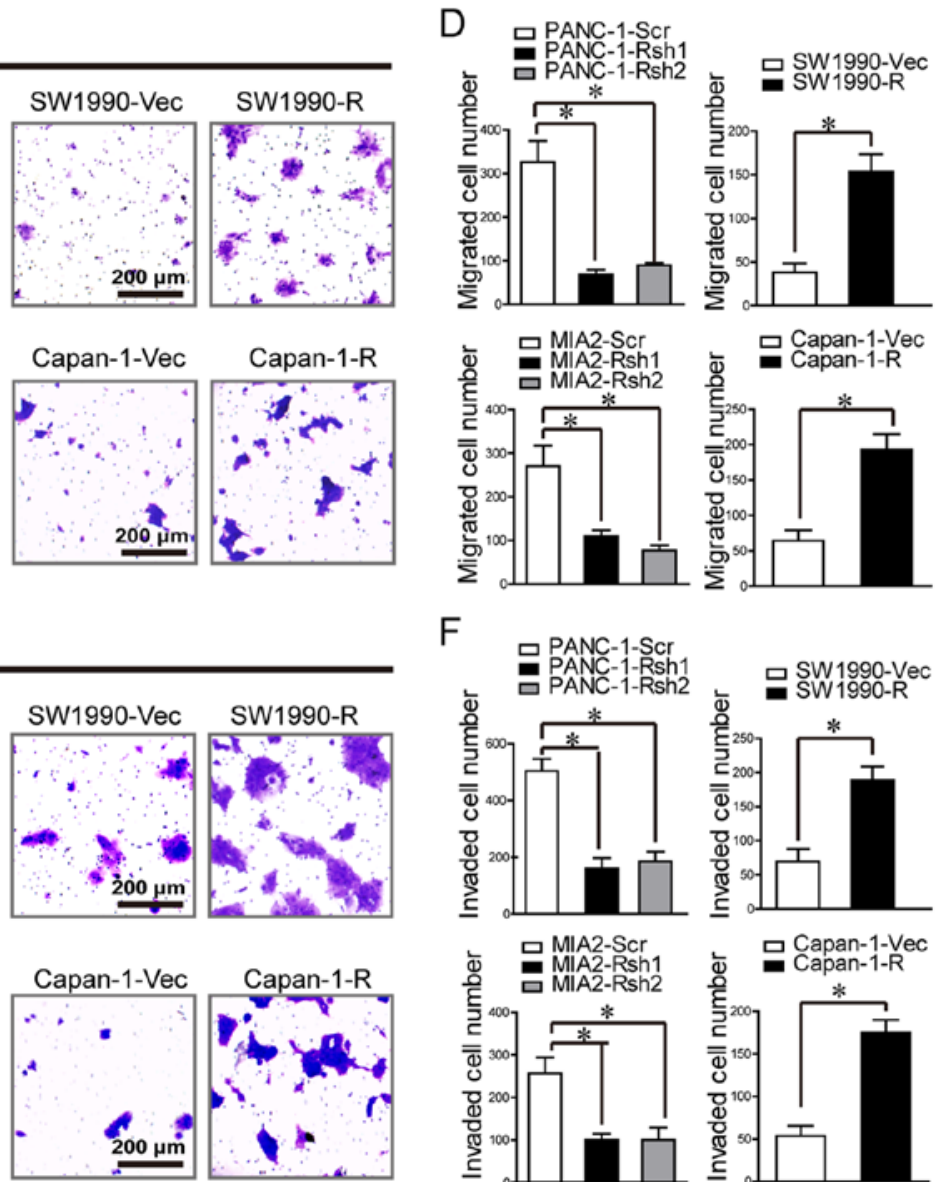

$\mathrm{F}$
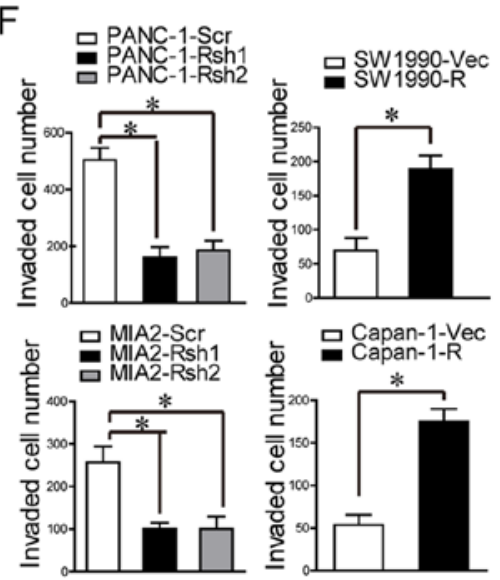

G

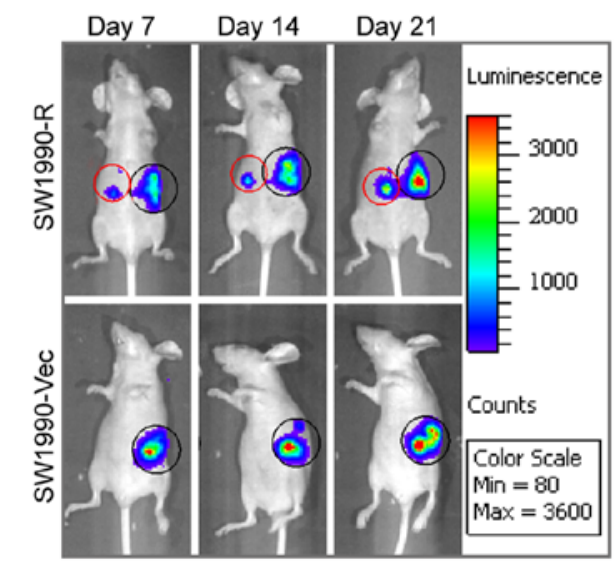

$\mathrm{H}$

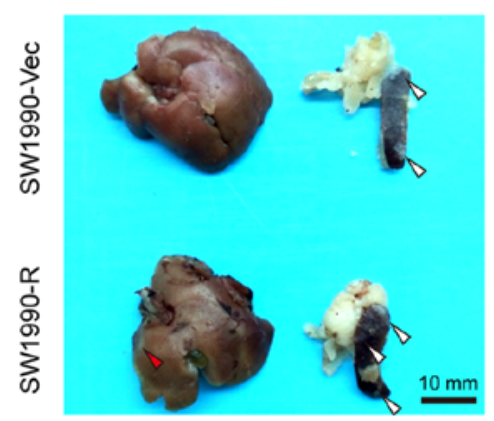

Figure 2. Receptor-interacting protein kinases 4 (RIPK4) promotes pancreatic cancer cell migration and invasion in vitro and invivo. (A) RIPK4 expression in PDAC cell lines was examined by western blot analysis. (B) RIPK4 was overexpressed in Capan-1 and SW1990 cells, and knocked down in PANC-1 and MIA PaCa-2 cells. (C-F) The effects of RIPK4 on cell (C and D) migration and (E and F) invasion were determined by Transwell assays using cells in which RIPK4 was overexpressed or knocked down. The quantification of 3 randomly selected fields is shown. All ${ }^{*} \mathrm{P}<0.05$. (G) Bioluminescence imaging of xenograft tumors in nude mice. Spleen tumors are indicted by black circles, and liver metastatic tumors are indicated by red circles. (H) Tumors in the spleen and liver of nude mice. White arrows indicate the tumor in the spleen. Red arrows indicate the metastatic tumor in the liver. Scale bar, $10 \mathrm{~mm}$.

cells: $38 \pm 18$ vs. $153 \pm 35, \mathrm{P}<0.05$; SW1990 invading cells: $69 \pm 32$ vs. $189 \pm 34, \mathrm{P}<0.05$ (Capan-1-Vec vs. Capan-1-R, respectively and SW1990-Vec vs. SW1990-R) (Fig. 2C-F)].
We then injected luciferase-tagged SW1990 cells overexpressing RIPK4 into the spleens of nude mice. At week 3, increased liver metastasis was observed in the RIPK4 
overexpression group (SW1990-R) compared to the control group (SW1990-Vec). The liver metastasis rate was 83\% (5 of 6) in the RIPK4 overexpression group compared with $17 \%$ (1 of 6) in the control group (Fig. 2G and H). The loss- and gain-of-function assays performed in vitro and in vivo suggested that RIPK4 promoted pancreatic cancer cell migration.

RIPK4 promotes pancreatic cancer cell migration and invasion via the RAF1/MEK/ERK pathway. We performed a KEGG pathway enrichment analysis of differentially expressed genes (at least a 1.5-fold change, $\mathrm{P}<0.05$ ) between the two subgroups. These genes were mainly enriched in functional pathways that are critical in cancer, such as the MAPK, TGF- $\beta$ and Wnt signaling pathways (adjusted $\mathrm{P}<0.001$ ) (Fig. 3A). The results of western blot analysis revealed that RIPK4 knockdown induced RAF1, MEK1/2 and ERK1/2 inactivation in the PANC-1 and MIAPaCa- 2 cells, as indicated by reduced phosphorylation. Consistently, RIPK4 overexpression enhanced RAF1, MEK1/2 and ERK1/2 phosphorylation in the Capan-1 and SW1990 cells (Fig. 3B). However, the levels of total Smad2 and phospho-Smad 2 in the TGF- $\beta$ signaling pathway and GSK-3 $\beta$, phospho-GSK-3 $\beta$, and phospho- $\beta$-catenin in the Wnt signaling pathway remained unaltered, irrespective of RIPK4 expression (Fig. 3C). These thus data indicate that RIPK4 may be associated with the activation of RAF1/MEK/ERK signaling. We therefore wished to determine whether the blocking of the activation of RAF1/MEK/ERK signaling can alter the impact of RIPK4 on tumor metastasis. Treatment of RIPK4-overexpressing cells with U0126 (a highly selective inhibitor of MEK1/2) significantly reduced cell migration and invasion in vitro. Transwell assays revealed that U0126 decreased the number of migrating/invading Capan-1 and SW1990 RIPK4overexpressing cells [Capan-1 migrating cells: $147 \pm 38$ vs. $43 \pm 22$, $\mathrm{P}<0.05$; Capan-1 invading cells: $195 \pm 38$ vs. $33 \pm 20, \mathrm{P}<0.05$; and SW1990 migrating cells: $168 \pm 54$ vs. $59 \pm 21, \mathrm{P}<0.05$; SW1990 invading cells: $128 \pm 36$ vs. $46 \pm 23, \mathrm{P}<0.05$ (SW1990-R vs. SW1990-R + U0126 and Capan-1-R vs. Capan-1-R + U012) (Fig. 3D and E)]. Collectively, these data demonstrate that RIPK4 promotes pancreatic cancer cell migration and invasion via the RAF1/MEK/ERK pathway.

PEBPI mediates the interaction between RIPK4 and the $R A F 1 / M E K / E R K$ pathway. We performed a protein interaction network analysis to elucidate the mechanisms through which RIPK4 induces RAF1/MEK/ERK signaling. The network predicted that PEBP1 played a critical role in the interaction between RIPK4 and the activation of RAF1/MEK/ERK signaling (Fig. 4A). We examined PEBP1 expression by RT-PCR and western blot analysis in the cells in which RIPK4 was overexpressed or knock down. The results revealed that the PEBP1 mRNA levels were not significantly altered (Fig. 4B and C). Of note, the PEBP1 protein level inversely correlated with RIPK4 expression; however, PEBP1 phosphorylation was not markedly affected by RIPK4 expression (Fig. 4D and E). Consistent with this finding, a negative correlation between RIPK4 and PEBP1 was also observed in 34 pancreatic cancer patient tissues ( $\mathrm{P}=0.0418$ with Pearson's $\chi^{2}$ test) (Fig. $4 \mathrm{~F}$ and $\left.\mathrm{G}\right)$. These results suggest that RIPK4 regulates PEBP1 expression at the post-translational level. We then treated RIPK4-overexpressing cells with MG132 (an inhibitor of the 26S proteasome) to examine whether PEBP1 is regulated through classic protein degradation. The inhibition of proteolysis by MG132 almost eliminated the change in the PEBP1 protein level induced by RIPK4 overexpression (Fig. 4H). Collectively, these findings suggest that the negative interplay between RIPK4 and BEBP1 is largely regulated through proteasome-mediated protein degradation.

Suppression of PEBPI degradation attenuates RIPK4-induced RAF1/MEK/ERK pathway activation and pancreatic tumor cell migration and invasion. We then examined the effect of PEBP1 on RIPK4-mediated activation of RAF1/MEK/ERK signaling and tumor cell migration and invasion. The results of western blot analysis revealed that the phosphorylation of RAF1, MEK1/2 and ERK1/2 induced by RIPK4 overexpression was almost fully prevented by the suppression of PEBP1 degradation with MG132 (Fig. 5A). Furthermore, RIPK4 overexpression-mediated cell migration and invasion were significantly abolished by the suppression of PEBP1 degradation in the Capan-1 and SW1990 cells [Capan-1 migrating cells: $144 \pm 39$ vs. $59 \pm 13, \mathrm{P}<0.05$; Capan-1 invading cells: $181 \pm 32$ vs. $53 \pm 6, \mathrm{P}<0.05$; and SW1990 migrating cells: $432 \pm 56$ vs. $150 \pm 27, \mathrm{P}<0.05$; SW1990 invading cells: $313 \pm 66$ vs. $132 \pm 8, \mathrm{P}<0.05$ (Capan-1-R vs. Capan-1-R + MG132 and SW1990-R vs. SW1990-R + MG132) (Fig. 5B and C)]. These results indicate that RIPK4 promotes tumor cell metastasis at least partly by down-regulating PEBP1 expression.

\section{Discussion}

We previously identified a unique subgroup of patients with pancreatic cancer with a pre-operative serum signature of $\mathrm{CEA}^{+} / \mathrm{CA} 125^{+} / \mathrm{CA} 19-9 \geq 1,000 \mathrm{U} / \mathrm{ml}$. These patients usually have poor surgical outcomes and are more likely to experience distant metastasis within 6 months after radical surgery (7). The molecular mechanisms underlying this aggressive phenotype remain unclear. In this study, we thus performed a high-throughput gene expression screen to identify key molecules or signaling pathways involved in the metastatic potential of the patients with this serum signature. Patients with pre-operative serum levels of CEA-/CA125-/CA19-9 $\leq 37 \mathrm{U} / \mathrm{ml}$ and a DFS of $\geq 24$ months were included as the control group. This analysis revealed that RIPK4 was one of the most critical genes upregulated in the subgroup of patients with pre-operative serum levels of $\mathrm{CEA}^{+} / \mathrm{CA} 125^{+} / \mathrm{CA} 19-9$ $\geq 1,000 \mathrm{U} / \mathrm{ml}$, and this significantly correlated with the prognosis of patients with pancreatic cancer. As the role of RIPK4 in cancer has been reported previously, we mainly examined the function of RIPK4 in pancreatic cancer metastasis.

Our clinical relevance analysis revealed a higher RIPK4 expression in pancreatic cancer tissues compared to normal pancreatic tissues. Notably, an increased RIPK4 expression predicted a poor OS and DFS. Functional assays demonstrated that RIPK4 promoted pancreatic cancer cell migration and invasion in vitro and in vivo. KEGG pathway enrichment analysis of differentially expressed genes indicated that MAPK signaling may play an important role in the high metastatic potential in this group of pancreatic cancer patients. To although no studies have reported that RIPK4 regulates MAPK signaling (at least to the best of our knowledge), crosstalk 
A

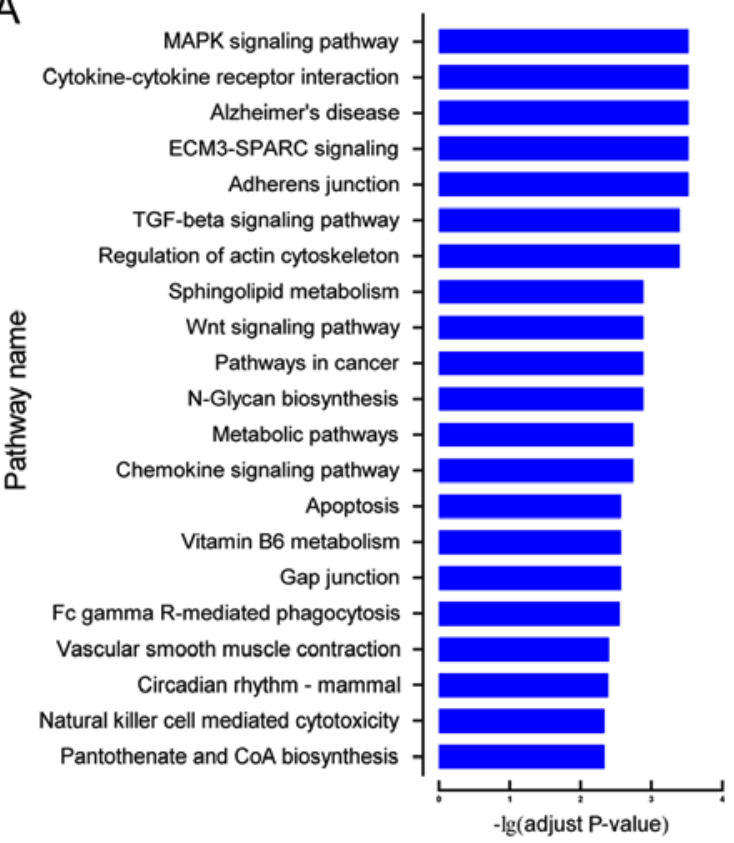

C

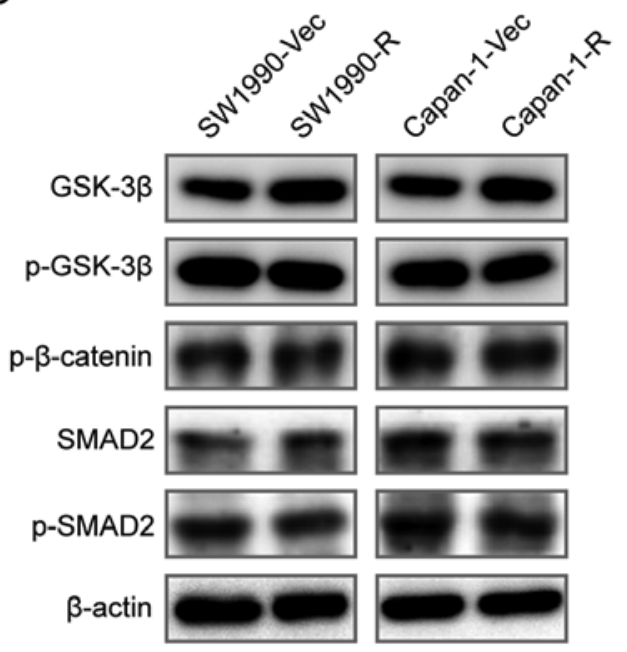

B

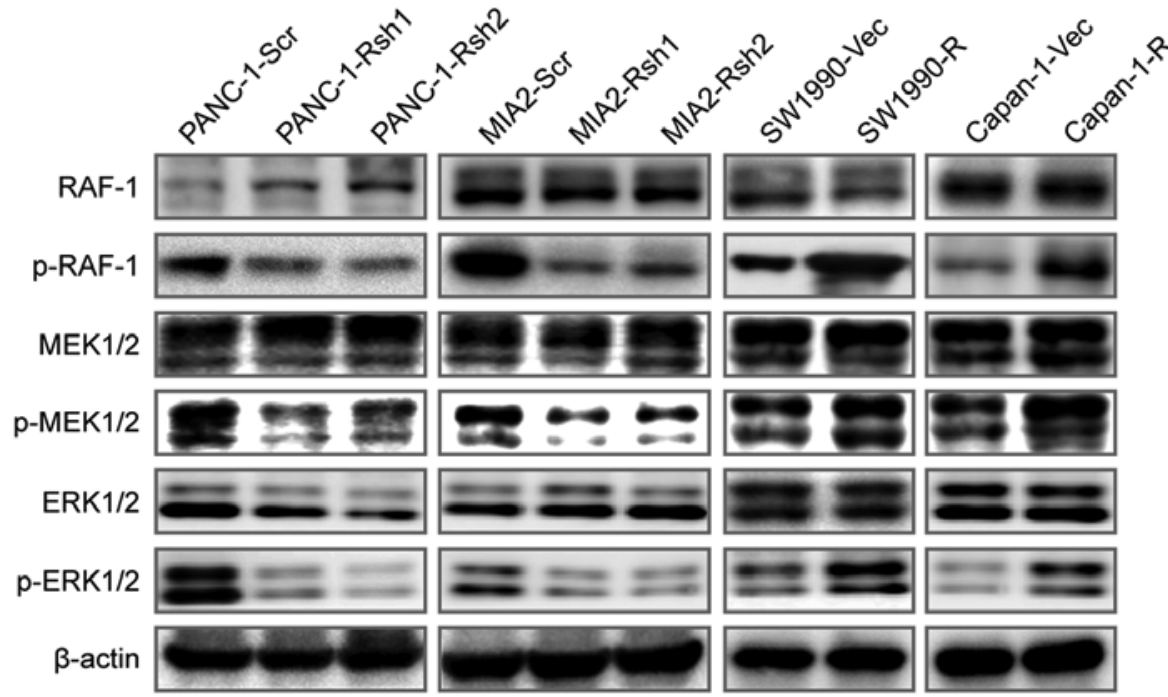

D

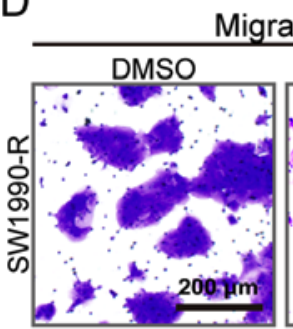

Migration
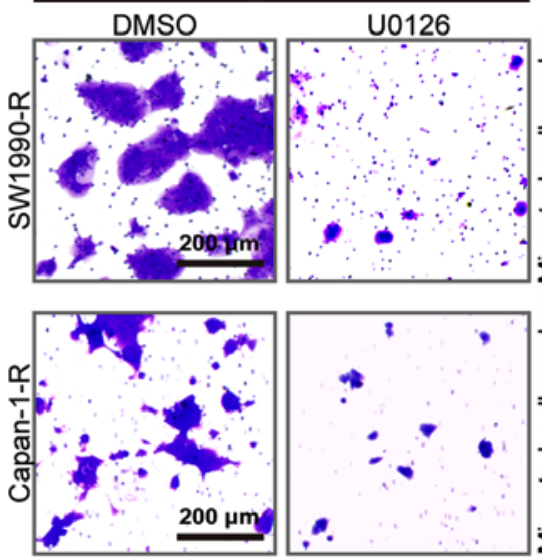

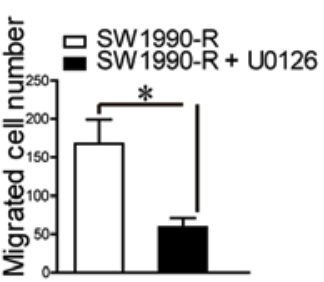

E Invasion
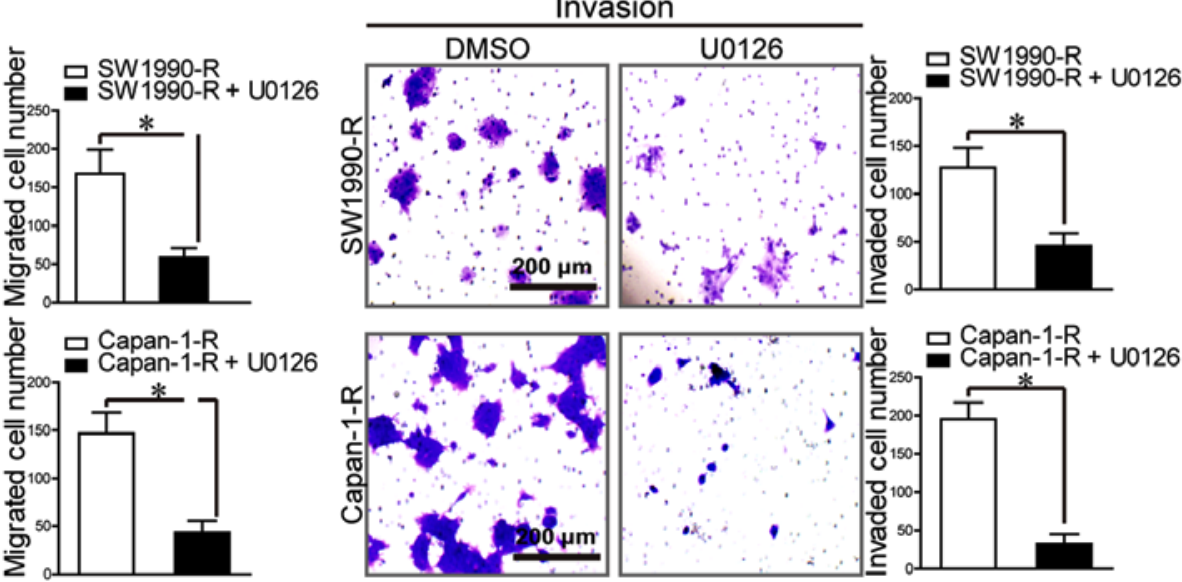

Figure 3. Receptor-interacting protein kinases 4 (RIPK4) promotes pancreatic cancer tumor cell metastasis via the RAF1/MEK/ERK pathway. (A) Pathway enrichment analysis of differentially expressed genes using the KEGG pathway database. (B) The levels of total and phosphorylated RAF1, MEK1/2 and ERK1/2

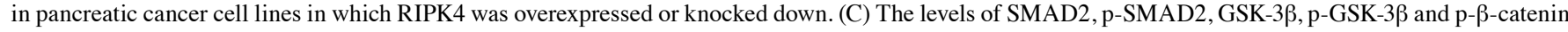
in pancreatic cancer cell lines in which RIPK4 was overexpressed were detected by western blot analysis. (D and E) The effects of blocking RAF1/MEK/ERK signaling on pancreatic cancer cell (D) migration and (E) invasion were determined by Transwell assays using RIPK4-overexpressing Capan-1 and SW1990 cell lines. The numbers of migrating or invading cells were calculated, and the quantification of 3 randomly selected fields is shown in the histogram. ${ }^{~} \mathrm{P}<0.05$. 
A

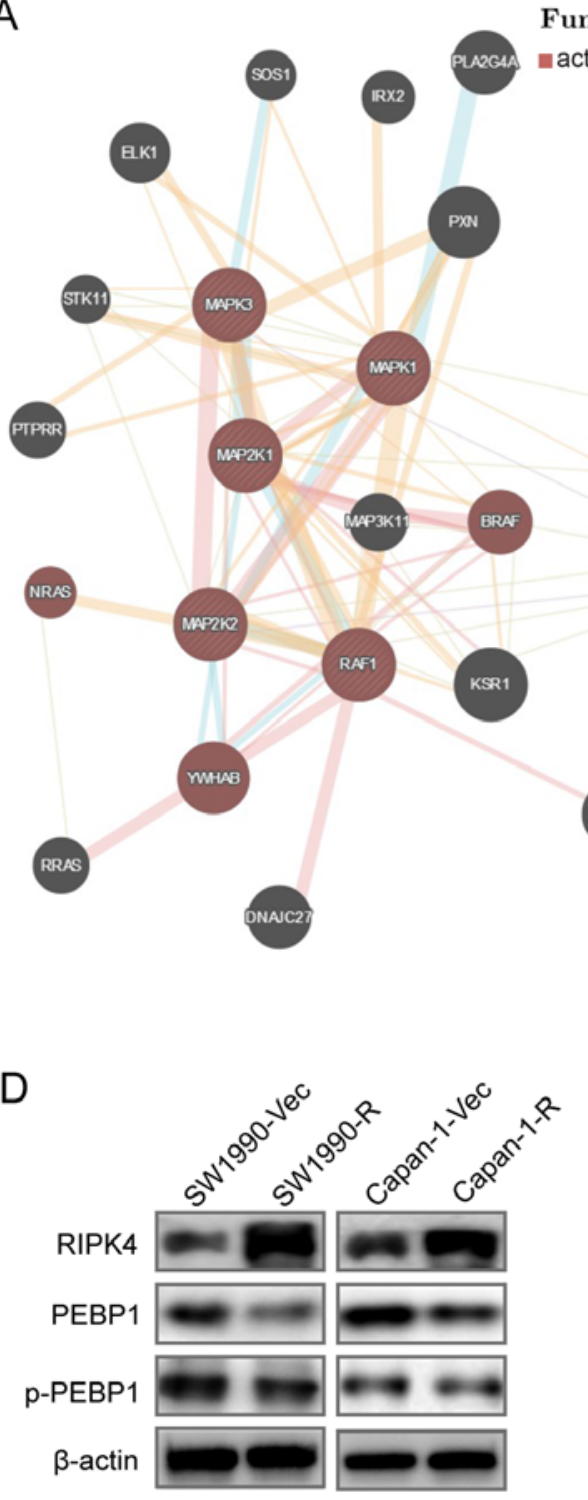

Networks

activation of MAPKK activity $=$ Predicted

= Co-expression

= Physical Interactions

= Pathway

= Shared protein domains

= Genetic Interactions

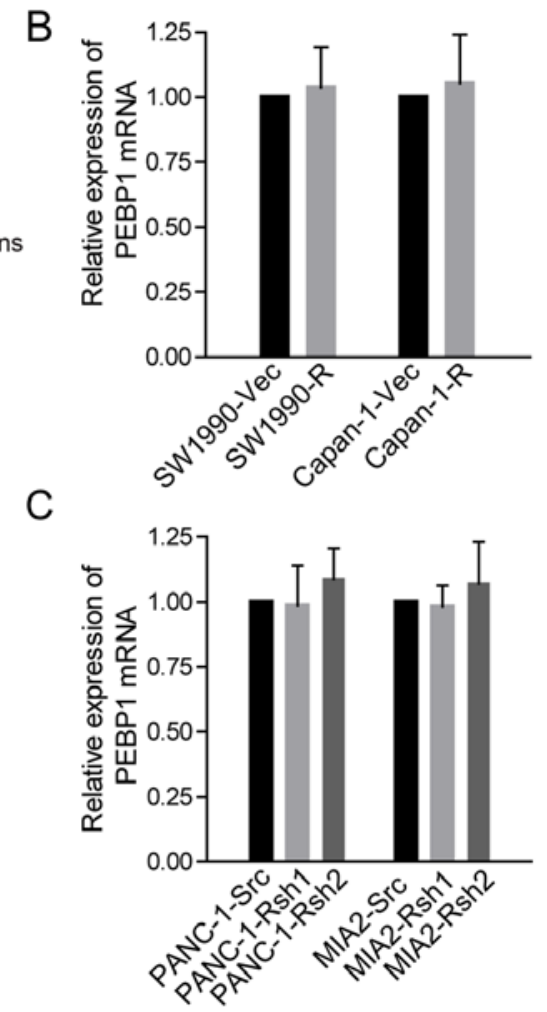

$\mathrm{F}$
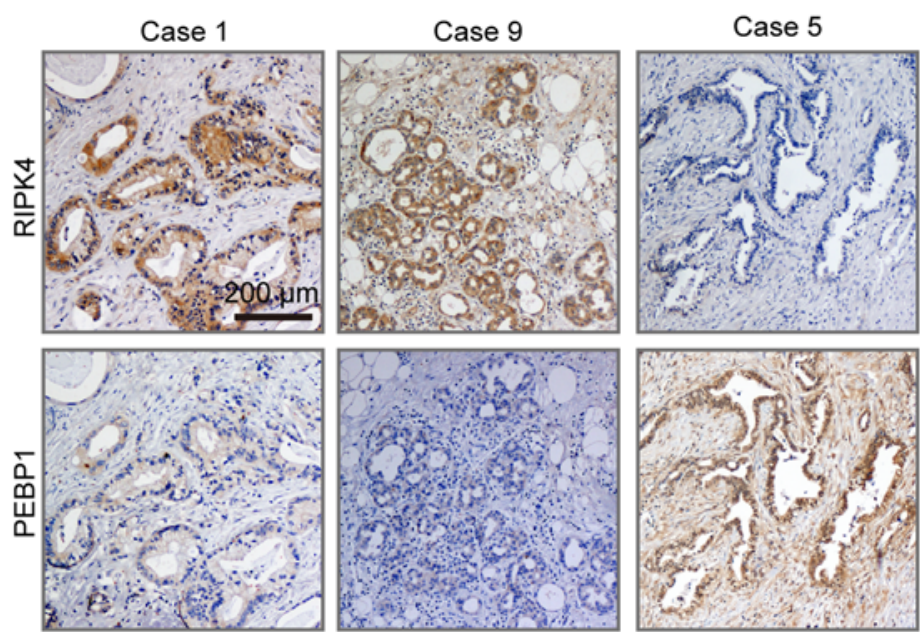

G

\begin{tabular}{l|c|c|c|}
\hline & PEBP1 high & PEBP1 low & Total \\
\hline RIPK4 high & 6 & 10 & 16 \\
\hline RIPK4 low & 13 & 5 & 18 \\
\hline Total & 19 & 15 & 34 \\
\hline
\end{tabular}

$\mathrm{H}$

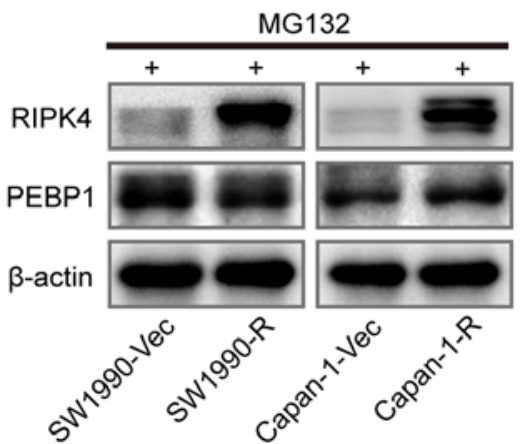

Figure 4. Phosphatidylethanolamine binding protein 1 (PEBP1) mediates the interaction between receptor-interacting protein kinases 4 (RIPK4) and RAF1/MEK/ERK signaling and has an inverse relationship with RIPK4. (A) The network analysis between RIPK4 and the RAF1/MEK/ERK signaling pathway. (B and C) PEBP1 mRNA expression in pancreatic cancer cells in which RIPK4 was (B) overexpressed or (C) knocked down. (D and E) Total and phosphorylated PEBP1 protein levels in pancreatic cancer cells in which RIPK4 was (D) overexpressed or (E) knocked down. (F and G) RIPK4 and PEBP1 expression exhibited an inverse correlation in pancreatic cancer patient tissue samples ( $\mathrm{P}=0.0418$ with Pearson's $\chi^{2}$ test). (H) PEBP1 protein levels in RIPK4-overexpressing and control cells following treatment with MG132 (an inhibitor of the 26S proteasome). 
A

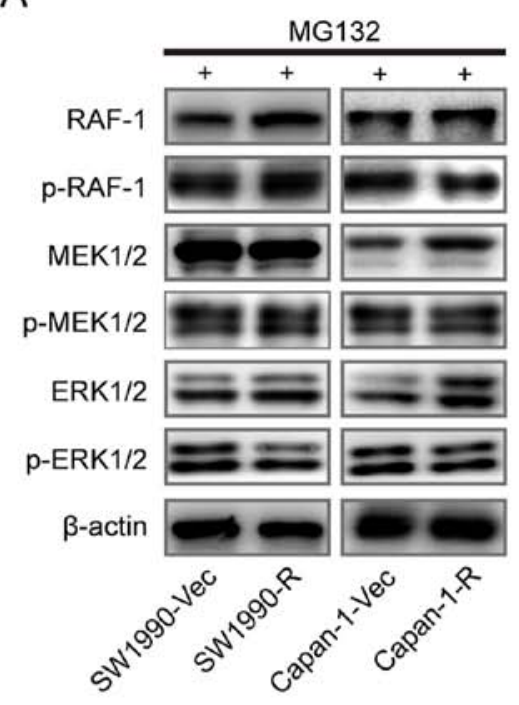

D

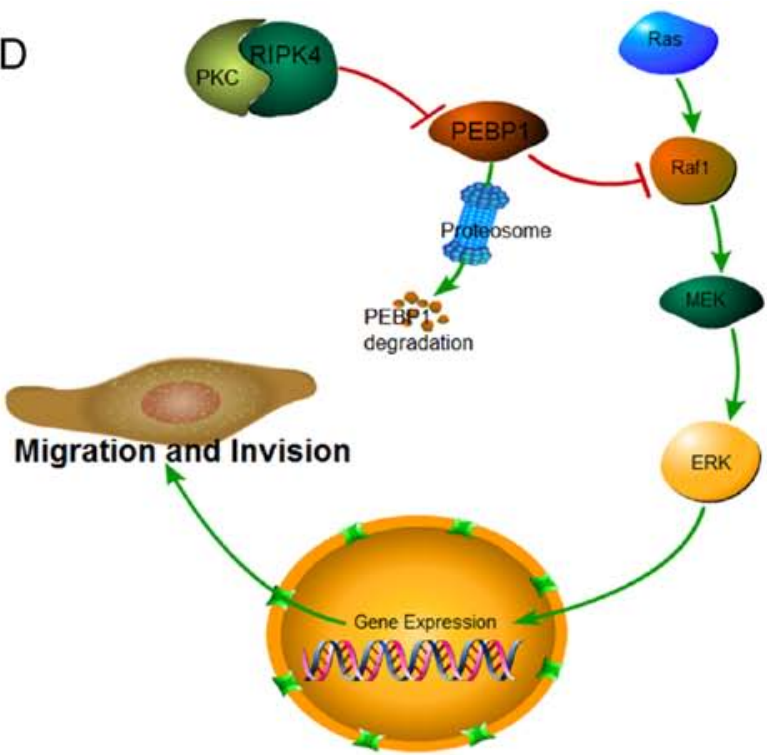

B

B
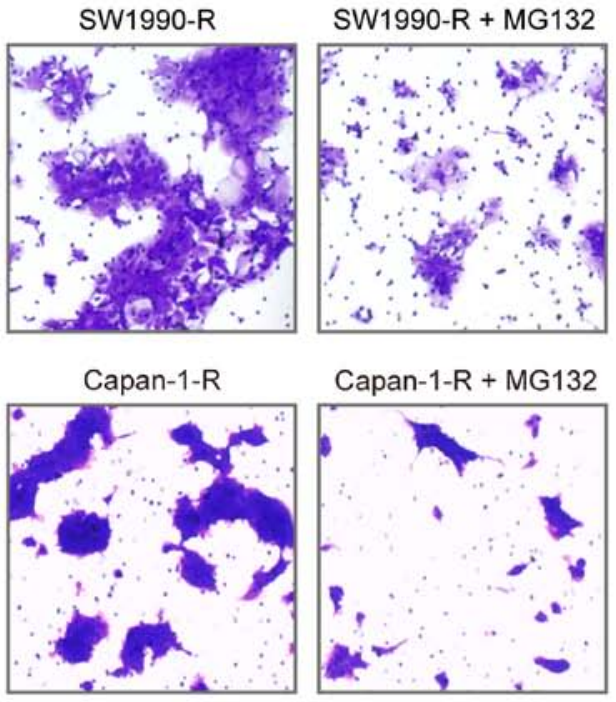

$200 \mu \mathrm{m}$
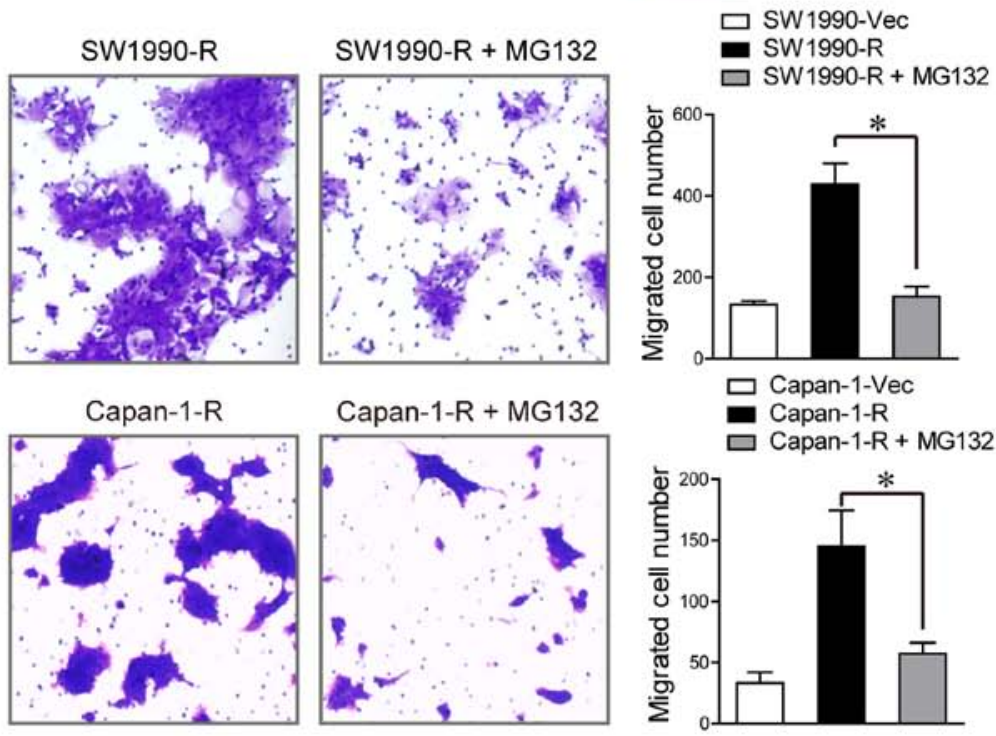
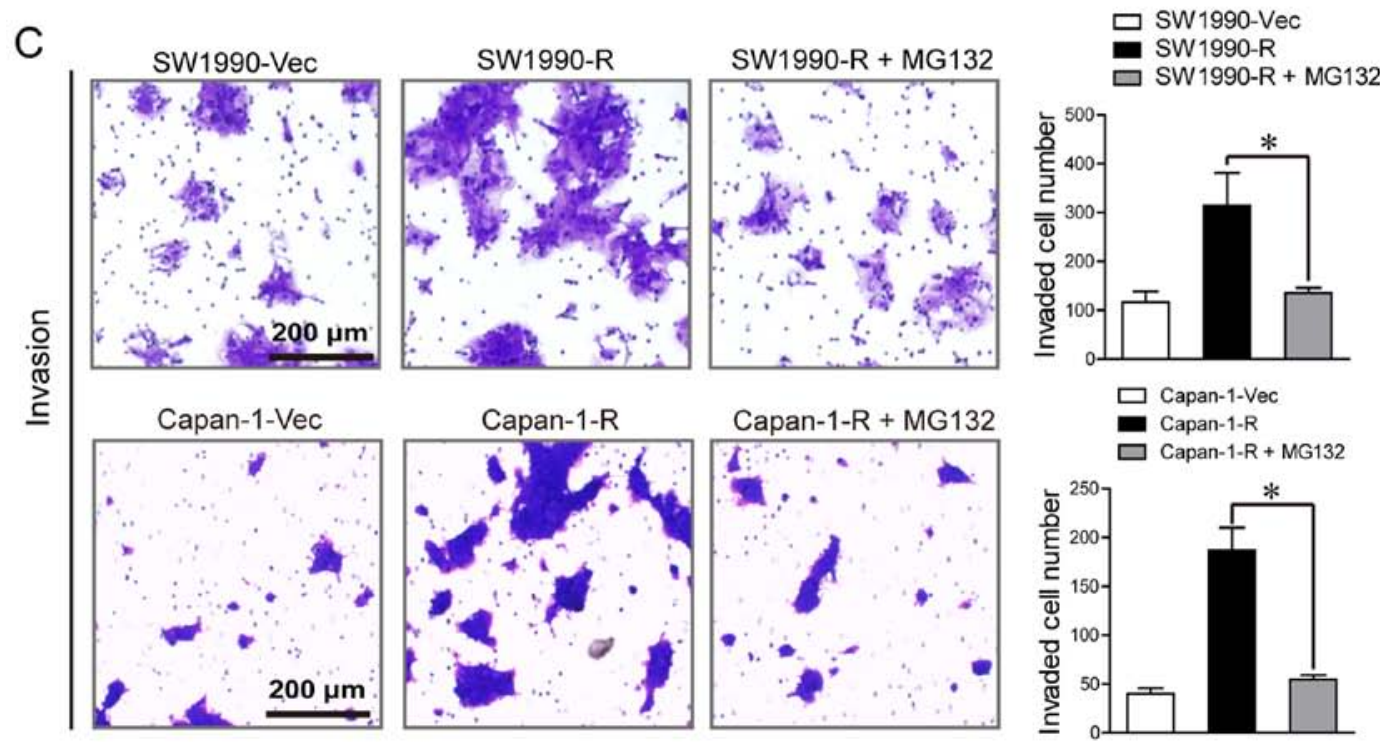

Figure 5. Suppression of phosphatidylethanolamine binding protein 1 (PEBP1) degradation eliminates the receptor-interacting protein kinases 4 (RIPK4)-induced activation of the RAF1/MEK/ERK pathway and pancreatic cancer cell migration and invasion. (A) Total and phosphorylated levels of RAF1, MEK1/2 and ERK1/2 in RIPK4-overexpressing and control cells following treatment with MG132 (an inhibitor of the 26S proteasome). (B and C) The effects of MG132-mediated suppression of PEBP1 degradation on RIPK4-overexpressing pancreatic cancer cell (B) migration and (C) invasion. (D) Proposed model of the mechanisms through which RIPK4 promotes pancreatic cancer cell migration and invasion via the PEBP1 degradation-induced activation of the RAF1/MEK/ERK pathway. 
between PKC and the MAPK pathway has been reported (25). PKC $\delta$ has been found to participate in ERK activation (26). Of note, the interaction between PKC $\delta$ and RIPK4 has been observed only for the catalytic domain of PKCס, not for the regulatory domain (8). It is therefore reasonable to assume that RIPK4 is a downstream signaling molecule of PKC $\delta$ and may serve as an intermediary in PKC $\delta$ and MAPK pathway activation. This hypothesis is supported by our findings that RIPK4 expression did not affect PKC phosphorylation (data not shown). However, RIPK4 obviously regulated the phosphorylation of RAF1, MEK1/2 and ERK1/2. Blocking the activation of RAF1/MEK/ERK signaling pathway significantly reduced cell migration and invasion in vitro. Collectively, these results suggest that RIPK4 promotes pancreatic cancer cell migration and invasion via the RAF1/MEK/ERK pathway.

A protein interaction network analysis predicted that PEBP1 plays a critical role in mediating the interaction between RIPK4 and RAF1/MEK/ERK activation. PEBP1 is a physiological endogenous inhibitor of the RAF1/MEK/ERK pathway that can inhibit pancreatic cancer cell proliferation, migration and invasion (27); however, its association with RIPK4 remains unclear. PEBP1 can act as a signaling switch between the PKC and RAF1/MEK/ERK signaling cascades (20). The PKC-mediated phosphorylation of PEBP1 on serine 153 abrogates its ability to bind to RAF1 and inhibit downstream MAPK signaling (21). Only classic and atypical, but not novel PKC isoforms phosphorylate PEBP1 at this residue $(26,28)$. This suggests that $\mathrm{PKC} \delta$ may be ineffective, and that the regulatory effects of PKC $\delta$ on RAF1/MEK/ERK signaling may not be due to PEBP1 phosphorylation. Similarly, RIPK4 may also not regulate PEBP1 phosphorylation. This is suggested by our result showing that RIPK4 did not affect PEBP1 phosphorylation at serine 153 . We did find a negative correlation between RIPK4 and PEBP1 expression in tissues from patients with pancreatic cancer, and RIPK4 reduced PEBP1 expression by inducing proteasome-mediated degradation. This result is consistent with a report that the steady state of total PEBP1 protein expression is regulated through proteasome-mediated degradation (21). Of note, non-phosphorylated PEBP1 is more likely to be degraded by proteasome-mediated degradation $(21,29)$. Therefore, as a protein kinase that interacts with PKCס, RIPK4 may activate RAF1/MEK/ERK signaling by inducing proteasome-mediated PEBP1 degradation rather than regulating PEBP1 phosphorylation.

In conclusion, this study reveals an elevated RIPK4 expression in a unique subgroup of patients with pancreatic cancer with levels of $\mathrm{CEA}^{+} / \mathrm{CA}_{125} / \mathrm{CA} 19-9 \geq 1,000 \mathrm{U} / \mathrm{ml}$. RIPK4 overexpression markedly promoted pancreatic cancer cell migration and invasion via RAF1/MEK/ERK activation. RIPK4 may stimulate RAF1/MEK/ERK signaling by inducing proteasome-mediated PEBP1 degradation. The direct mechanisms underlying RIPK4induced proteasome-mediated PEBP1 degradation remains unclear. Future studies are warranted to determine whether other genes identified in the microarray are associated with the high metastatic potential of pancreatic cancer.

\section{Acknowledgements}

The authors would like to thank Huan-Yu Xia and Ying Yang for their assistance in collecting the patient data.

\section{Funding}

This study was supported by grants from the National Science Foundation for Distinguished Young Scholars of China (no. 81625016) and the National Natural Science Foundation of China (nos. 81472670, 81402397 and 81402398). The funding agencies had no role in the study design, data collection and analyses, decision to publish, or preparation of this manuscript.

\section{Availability of data and materials}

The analyzed data sets generated during the study are available from the corresponding author on reasonable request.

\section{Authors' contributions}

ZHQ,HXX and LL were responsible for the study design, original article drafting and editing, data acquisition and data analysis. WQW and WJ were responsible for article revision. HLG was responsible for data analysis. SRZ and JZX were responsible for data acquisition and patient follow-up. CTW were responsible for data interpretation and methodology. SL was responsible for patient follow-up. QXN was responsible for supervision. XJY was responsible for funding acquisition and supervision.

\section{Ethics approval and consent to participate}

The use of human tissues was approved by the Fudan University Shanghai Cancer Center Institutional Research Ethics Committee and patient consent was obtained.

\section{Consent for publication}

Not applicable.

\section{Competing interests}

The authors declare that they have no competing interests.

\section{References}

1. Long J, Luo GP, Xiao ZW, Liu ZQ, Guo M, Liu L, Liu C, Xu J, Gao YT, Zheng Y, et al: Cancer statistics: Current diagnosis and treatment of pancreatic cancer in Shanghai, China. Cancer Lett 346: 273-277, 2014

2. Siegel RL, Miller KD and Jemal A: Cancer Statistics, 2017. CA Cancer J Clin 67: 7-30, 2017.

3. Koay EJ, Amer AM, Baio FE, Ondari AO and Fleming JB: Toward stratification of patients with pancreatic cancer: Past lessons from traditional approaches and future applications with physical biomarkers. Cancer Lett 381: 237-243, 2016.

4. Hackert T, Ulrich A and Büchler MW: Borderline resectable pancreatic cancer. Cancer Lett 375: 231-237, 2016.

5. Hartwig W, Werner J, Jäger D, Debus J and Büchler MW: Improvement of surgical results for pancreatic cancer. Lancet Oncol 14: e476-e485, 2013.

6. Kamisawa T, Wood LD, Itoi T and Takaori K: Pancreatic cancer. Lancet 388: 73-85, 2016.

7. Liu L, Xu H, Wang W, Wu C, Chen Y, Yang J, Cen P, Xu J, Liu C Long $\mathrm{J}$, et al: A preoperative serum signature of $\mathrm{CEA}^{+} / \mathrm{CA} 125^{+}$ CA19-9 $\geq 1000 \mathrm{U} / \mathrm{ml}$ indicates poor outcome to pancreatectomy for pancreatic cancer. Int J Cancer 136: 2216-2227, 2015.

8. Bhr C, Rohwer A, Stempka L, Rincke G, Marks F and Gschwendt M: DIK, a novel protein kinase that interacts with protein kinase Cdelta. Cloning, characterization, and gene analysis. J Biol Chem 275: 36350-36357, 2000. 
9. Zhang D, Lin J and Han J: Receptor-interacting protein (RIP) kinase family. Cell Mol Immunol 7: 243-249, 2010.

10. Azizmohammadi S, Azizmohammadi S, Safari A, Kaghazian M, Sadrkhanlo M,Behnod V and Seifoleslami M: High-level expression of RIPK4 and EZH2 contributes to lymph node metastasis and predicts favorable prognosis in patients with cervical cancer. Oncol Res 25: 495-501, 2017.

11. Liu DQ, Li FF, Zhang JB, Zhou TJ, Xue WQ, Zheng XH, Chen YB, Liao XY, Zhang L, Zhang SD, et al: Increased RIPK4 expression is associated with progression and poor prognosis in cervical squamous cell carcinoma patients. Sci Rep 5: 11955, 2015.

12. Huang X, McGann JC, Liu BY, Hannoush RN, Lill JR, Pham V, Newton K, Kakunda M, Liu J, Yu C, et al: Phosphorylation of Dishevelled by protein kinase RIPK4 regulates Wnt signaling. Science 339: 1441-1445, 2013.

13. Lee P, Jiang S, Li Y, Yue J, Gou X, Chen SY, Zhao Y, Schober M, Tan M and Wu X: Phosphorylation of Pkpl by RIPK4 regulates epidermal differentiation and skin tumorigenesis. EMBO J 36 : 1963-1980, 2017

14. Wang X, Zhu W, Zhou Y, Xu W and Wang H: RIPK4 is downregulated in poorly differentiated tongue cancer and is associated with migration/invasion and cisplatin-induced apoptosis. Int J Biol Markers 29: e150-e159, 2014.

15. Yeung K, Janosch P, McFerran B, Rose DW, Mischak H, Sedivy JM and Kolch W: Mechanism of suppression of the Raf/MEK/extracellular signal-regulated kinase pathway by the raf kinase inhibitor protein. Mol Cell Biol 20: 3079-3085, 2000.

16. Yeung K, Seitz T, Li S, Janosch P, McFerran B, Kaiser C, Fee F, Katsanakis KD, Rose DW, Mischak H, et al: Suppression of Raf-1 kinase activity and MAP kinase signalling by RKIP. Nature 401: 173-177, 1999.

17. Song SP, Zhang SB, Li ZH, Zhou YS, Li B, Bian ZW, Liao QD and Zhang YD: Reduced expression of Raf kinase inhibitor protein correlates with poor prognosis in pancreatic cancer. Clin Transl Oncol 14: 848-852, 2012.

18. Karamitopoulou E, Zlobec I, Gloor B, Kondi-Pafiti A, Lugli A and Perren A: Loss of Raf-1 kinase inhibitor protein (RKIP) is strongly associated with high-grade tumor budding and correlates with an aggressive phenotype in pancreatic ductal adenocarcinoma (PDAC). J Transl Med 11: 311, 2013.

19. Kim HS, Kim GY, Lim SJ and Kim YW: Loss of Raf-1 kinase inhibitory protein in pancreatic ductal adenocarcinoma. Pathology 42: 655-660, 2010

20. Hellmann J, Rommelspacher H and Wernicke C: Long-term ethanol exposure impairs neuronal differentiation of human neuroblastoma cells involving neurotrophin-mediated intracellular signaling and in particular protein kinase C. Alcohol Clin Exp Res 33: 538-550, 2009.
21. Moen EL, Wen S, Anwar T, Cross-Knorr S, Brilliant K, Birnbaum F, Rahaman S, Sedivy JM, Moss SF and Chatterjee D: Regulation of RKIP function by Helicobacter pylori in gastric cancer. PLoS One 7: e37819, 2012.

22. Furukawa T, Duguid WP, Rosenberg L, Viallet J, Galloway DA and Tsao MS: Long-term culture and immortalization of epithelial cells from normal adult human pancreatic ducts transfected by the E6E7 gene of human papilloma virus 16. Am J Pathol 148: 1763-1770, 1996.

23. Qi Z, Liu M,Liu Y,Zhang M and Yang G: Tetramethoxychalcone, a chalcone derivative, suppresses proliferation, blocks cell cycle progression, and induces apoptosis of human ovarian cancer cells. PLoS One 9: e106206, 2014.

24. Warde-Farley D, Donaldson SL, Comes O, Zuberi K, Badrawi R, Chao P, Franz M, Grouios C, Kazi F, Lopes CT, et al: The GeneMANIA prediction server: Biological network integration for gene prioritization and predicting gene function. Nucleic Acids Res 38 (Suppl 2): W214-W220, 2010.

25. Maines MD: Biliverdin reductase: PKC interaction at the crosstalk of MAPK and PI3K signaling pathways. Antioxid Redox Signal 9: 2187-2195, 2007.

26. Mugami S, Dobkin-Bekman M, Rahamim-Ben Navi L and Naor Z: Differential roles of PKC isoforms (PKCs) in $\mathrm{GnRH}$ stimulation of MAPK phosphorylation in gonadotrope derived cells. Mol Cell Endocrinol: Apr 6, 2017 (Epub ahead of print). doi: 10.1016/j.mce.2017.04.004.

27. Dai H, Chen H, Liu W, You Y, Tan J, Yang A, Lai X and Bie P: Effects of Raf kinase inhibitor protein expression on pancreatic cancer cell growth and motility: An in vivo and in vitro study. J Cancer Res Clin Oncol 142: 2107-2117, 2016.

28. Corbit KC, Trakul N, Eves EM, Diaz B, Marshall M and Rosner MR: Activation of Raf-1 signaling by protein kinase $C$ through a mechanism involving Raf kinase inhibitory protein. J Biol Chem 278: 13061-13068, 2003.

29. Baritaki S, Yeung K, Palladino M, Berenson J and Bonavida B: Pivotal roles of snail inhibition and RKIP induction by the proteasome inhibitor NPI-0052 in tumor cell chemoimmunosensitization. Cancer Res 69: 8376-8385, 2009.

This work is licensed under a Creative Commons Attribution-NonCommercial-NoDerivatives 4.0 International (CC BY-NC-ND 4.0) License. 